\title{
ANALISIS FAKTOR BRAND CITIZENSHIP BEHAVIOR PADA HOTEL SHERATON SURABAYA
}

\author{
Claudion Graciella ${ }^{1}$, Erica Dea Hutama ${ }^{2}$, Fransisca Andreani ${ }^{3}$ \\ 1,2,3 Program Manajemen Perhotelan, Program Studi, Manajemen, Fakultas Bisnis dan Ekonomi \\ Universitas Kristen Petra. Jl. Siwalankerto 121-131, Surabaya \\ Email: ${ }^{1}$ fioraangelica98@gmail.com; ${ }^{2}$ erica.hutamaa@gmail.com; ${ }^{3}$ andrea@petra.ac.id \\ *Penulis korespondensi
}

\begin{abstract}
Abstrak
Penelitian ini dilakukan untuk mengetahui faktor baru yang dapat terbentuk dari Brand Citizenship Behavior (BCB) di Hotel Sheraton Surabaya. BCB adalah perilaku karyawan yang mencerminkan merek organisasinya. Karena perilaku karyawan mencerminkan merek organisasinya, maka sangatlah penting untuk membentuk perilaku karyawan. Penelitian ini bertujuan mereduksi 7 faktor BCB (helping behavior, brand consideration, brand enthusiasm, sportsmanship, brand endorsement, self-development, brand advancement) dengan menggunakan Exploratory Factor Analysis (EFA). Hasil penelitian menunjukkan bahwa faktor baru yang terbentuk adalah helping behavior, brand enthusiasm, self-development, dan brand loyalty.
\end{abstract}

Kata kunci: Brand Citizenship Behavior (BCB), exploratory factor analysis.

\begin{abstract}
This study was conducted to determine new factors of Brand Citizenship Behavior $(B C B)$ in Sheraton Hotel Surabaya. BCB refers to employee behavior reflecting the organization brand. As employee behavior represents the organization brand, it is important to shape the behavior to reflect the organization brand. This study reduces 7 factors of BCB using Exploratory Factor Analysis. The results of this study show that the new factors are helping behavior, brand enthusiasm, self-development, and brand loyalty.
\end{abstract}

Keywords: Brand Citizenship Behavior (BCB), exploratory factor analysis.

\section{PENDAHULUAN}

Di Indonesia perkembangan industri perhotelan berkembang dengan sangat cepat. Pada tahun 2016 tercatat sebanyak 18.829 usaha akomodasi dengan jumlah kamar tersedia mencapai 527.176 kamar (Badan Pusat Statistik Indonesia, 2016). Sedangkan pada tahun 2018, 28.230 usaha akomodasi dengan jumlah kamar tersedia mencapai 712.202 kamar dan diantara usaha akomodasi tersebut, 3.314 usaha atau 11,74 persen merupakan hotel yang diklasifikasikan sebagai hotel berbintang dengan jumlah kamar sebanyak 278.522 unit (Badan Pusat Statistik Indonesia, 2018). Dengan semakin banyaknya hotel membuat persaingan semakin ketat. Oleh karena itu hotel harus dapat mempertahankan kualitas dan konsumennya. Dengan merek konsumen dapat mengidentifikasi dan membedakan hotel pilihannya dengan cepat (Prasad \& Dev, 2000).

King dan Grace (2007) menyatakan bahwa tujuan dari suatu merek adalah untuk mengidentifikasi produk atau layanan organisasi dari organisasi lainnya. Merek merupakan salah satu masalah penting di sebuah organisasi. Menurut Burmann dan Zeplin (2005), sama halnya seperti orang, merek juga perlu kredibilitas agar dapat dipercaya. Jika janji merek tidak dijaga secara konsisten dalam penyampaian layanan pada konsumen, maka kredibilitas dan kekuatan merek akan menurun. Karyawan mewakili merek sehingga memiliki peluang untuk meningkatkan citra merek dan reputasi serta kinerja merek melalui sikap dan perilaku karyawan, terutama selama penyampaian layanan (Burmann, Zeplin, \& Riley, 2008; King \& Grace, 2007; Burmann \& Zeplin, 2005).

Perilaku karyawan sangatlah penting bagi organisasi karena mewakili identitas merek organisasi. Identitas merek dibangun berdasarkan keputusan dan perilaku karyawan. Praktek Internal Brand Management (IBM) dapat meningkatkan pengetahuan dan komitmen pada merek, sehingga dapat meningkatkan perilaku karyawan yang semakin mencerminkan merek organisasi (Piehler, 2018). Brand Citizenship Behavior (BCB) merupakan intensi karyawan yang dengan sukarela menunjukkan perilaku yang melebihi harapan dan mencerminkan merek organisasi. Dalam aplikasinya Organisational Citizenship Behavior (OCB) dan 
BCB mempunyai banyak persamaan, tetapi BCB lebih mengarah pada perilaku yang mencerminkan nilainilai organisasi.

Peneliti melakukan penelitian di Hotel Sheraton Surabaya. Hotel Sheraton memiliki 3 nilai, yaitu Welcoming, Assuring, dan Community. Makna dari Welcoming adalah Hotel Sheraton menyambut konsumen yang bepergian agar merasa nyaman seperti di rumah. Kemudian Assured memiliki arti dimana Sheraton sebagai hotel yang penuh sejarah dalam industri perhotelan. Selanjutnya, Community yaitu Hotel Sheraton menjadi penghubung antar komunitas karena "We bring people together because we are better together" (Kami membawa masyarakat bersama-sama karena akan lebih baik jika bersama).

Hasil observasi peneliti menunjukkan ada perilaku karyawan Hotel Sheraton Surabaya yang mewakili faktor dari BCB. Sebagai contoh dari faktor helping behavior yaitu karyawan sering membantu menangani keluhan konsumen dari departemen lainnya. Berikutnya adalah cara karyawan berbicara antar kolega dan konsumen dengan sopan dan ramah adalah contoh dari brand consideration. Contoh lain dari faktor sportsmanship, yaitu para karyawan sering menunjukkan sikap inisiatif membantu dan tidak mengeluh saat harus lembur. Lalu, salah satu sikap brand endorsement adalah karyawan sering memberi komentar positif mengenai pekerjaannya di Hotel Sheraton. Selain itu, karyawan juga sering ikut pelatihan yang berkaitan dengan keterampilan dan cara melayani untuk dapat memberikan layanan yang lebih bagi konsumen yang mewakili faktor self-development. Lebih lanjut, yaitu setiap keluhan dari konsumen akan diteruskan dalam rapat agar ke depannya tidak terulang lagi; ini adalah contoh yang mewakili faktor brand advancement. Adapun tujuan dari penelitian ini adalah untuk mengetahui faktor baru apa yang terbentuk dari factor yang ada dalam BCB. Hal ini akan bermanfaat bagi Hotel Sheraton Surabaya untuk meningkatkan perilaku karyawannya dengan lebih baik yang mampu mencerminkan citra merek dari hotel.

\section{TEORI PENUNJANG}

\section{Organisational Citizenship Behavior (OCB)}

OCB merupakan teori dimana organisasi membutuhkan karyawannya untuk berperilaku lebih dari yang dituntut oleh organisasi (Ghozali, 2005). Menurut Podsakoff, MacKenzie, Paine \& Bachrach (2000) ada 7 faktor OCB, sebagai berikut:

1. Helping behavior merujuk pada perilaku sopan, sukarela membantu orang lain dan mencegah terjadinya masalah terkait pekerjaan.
2. Sportmanship mengacu pada kesediaan seseorang untuk mentolerir ketidaknyamanan atas beban pekerjaan tanpa mengeluh.

3. Organizational loyalty merupakan perilaku loyal terhadap organisasi dan merekomendasikan merek pada orang di luar perusahaan.

4. Organizational compliance merupakan perilaku yang mengikuti aturan organisasi yang ada, meskipun ketika tidak ada yang memantau.

5. Individual initiative mengacu pada perilaku yang meningkatkan kinerja karyawan, seperti mau membantu pekerjaan orang lain, berani mengambil tanggung jawab tambahan.

6. Civic virtue merujuk pada komitmen karyawan terhadap organisasi secara keseluruhan. Ini ditunjukkan dengan keinginan untuk berpatisipasi aktif dalam organisasi.

7. Self-development merupakan perilaku sukarela yang dilakukan karyawan untuk meningkatkan pengetahuan, keterampilan dan kemampuan karyawan.

\section{Brand Citizenship Behavior (BCB)}

Organisational Citizenship Behavior dan Brand Citizenship Behavior bukan dua topik yang berbeda. Menurut hasil wawancara yang dilakukan oleh Burmann dan Zeplin (2005), hakikat OCB dan BCB sama yaitu peran yang dilakukan seseorang melebihi dari yang seharusnya. BCB diadopsi dari OCB dan dimodifikasi dengan konteks yang mendukung dalam menghidupkan merek. Burmann menggunakan hasil penelitian Podsakoff et al. (2000) mengenai faktor OCB sebagai dasar faktor BCB. BCB memiliki lingkup yang lebih luas dari OCB karena perilaku targetnya sampai ke pihak eksternal. Sedangkan OCB lebih ke arah intraorganisasional.

Ada tujuh faktor BCB yang terdiri dari: helping behaviors, brand consideration, brand enthusiasm, brand sportsmanship, brand endorsement, selfdevelopment, dan brand advancement. Pada OCB, faktor yang pertama (helping behavior) lebih fokus pada pihak internal organisasi, sedangkan BCB lebih luas cakupannya hingga konsumen. Fokus BCB pada 6 faktor lainnya lebih sempit dari OCB karena lebih di fokuskan pada merek daripada keseluruhan organisasi.

\section{Faktor BCB}

Menurut Burmann dan Zeplin (2005), ada tujuh faktor Brand Citizenship Behavior yang rinciannya sebagai berikut:

1. Helping behavior merujuk pada sikap positif, keramahan, suka menolong dan empati terhadap konsumen internal dan eksternal, mengambil 


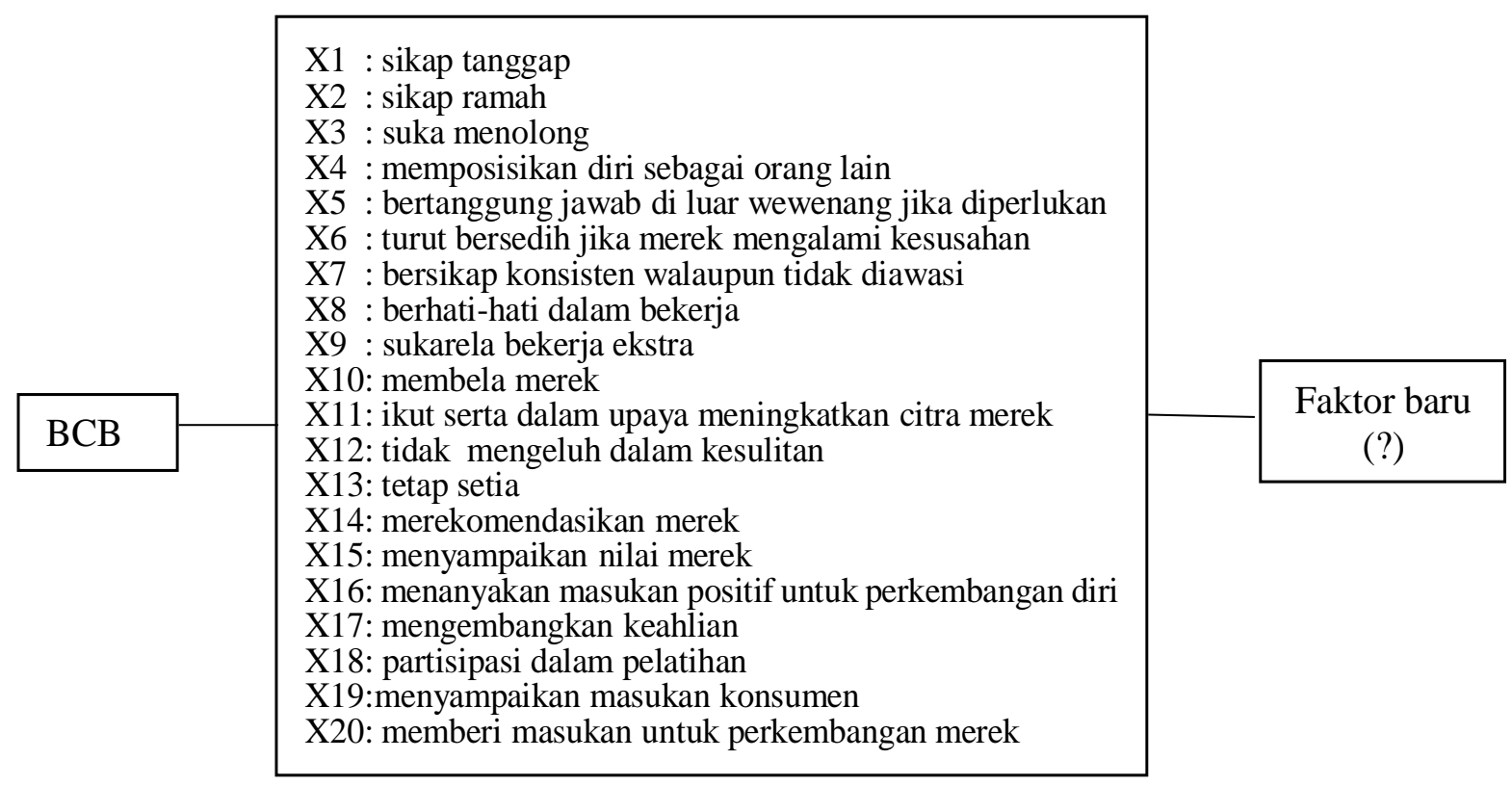

Gambar 1. Kerangka Berpikir

tanggung jawab untuk tugas-tugas di luar wilayah sendiri jika perlu.

2. Brand consideration adalah kepatuhan terhadap pedoman perilaku terkait merek dan refleksi dampak merek sebelum berkomunikasi atau mengambil tindakan dalam situasi apa pun.

3. Brand enthusiasm menunjukkan inisiatif ekstra saat terlibat dalam perilaku terkait merek.

4. SportsmanshipI adalah sikap tidak mengeluh, kesediaan untuk terlibat dengan merek.

5. Brand endorsement menunjukkan perilaku dalam merekomendasikan merek kepada orang lain bahkan dalam situasi yang tidak terkait dengan pekerjaan, misalnya memberikan identitas merek kepada pendatang baru di organisasi.

6. Self-development adalah kemauan karyawan untuk terus meningkatkan keterampilan terkait merek.

7. Brand advancement merujuk pada kontribusi karyawan dalam memberi dan meneruskan feedback konsumen atau menghasilkan ide-ide inovatif.

\section{METODE PENELITIAN}

Jenis penelitian yang digunakan adalah kurangtitatif. Populasi pada penelitian ini adalah karyawan aktif yang bekerja di Hotel Sheraton Surabaya, sebanyak 186 karyawan permanen dan 76 karyawan kontrak. Pengambilan sampel menggunakan judgemental sampling dengan kriteria sampel adalah karyawan tetap Hotel Sheraton yang telah bekerja minimum lebih dari 1 tahun kalau sudah dianggap sudah memahami nilai - nilai Hotel Sheraton Surabaya.
Kuesioner dibagikan pada 15 April 2020 hingga 29 April 2020 secara online dengan menggunakan google form dan dititipkan melalui HRD Hotel Sheraton Surabaya. Lalu HRD membantu menyebarkan kuesioner kepada 262 karyawan dan dari hasil penyebaran kuesioner peneliti mendapat 75 responden. Dikarenakan situasi pandemic covid saat penelitian, maka peneliti tidak melakukan penyebaran kuesioner secara offline.

Data pada penelitian ini menggunakan skala Likert dari 1 (sangat tidak setuju), 2 (tidak setuju), 3 (netral), 4 setuju, dan 5 (sangat setuju). Selain itu skala interval juga digunakan untuk melakukan kategori tingkat persetujuan responden. Data yang diperoleh diolah dengan bantuan software PLS. Analisis data menggunakan exploratory factor analysis.

\section{HASIL PENELITIAN DAN PEMBAHASAN}

Dari penyebaran kuesioner peneliti mendapatkan 75 responden namun ada 3 responden yang belum bekerja lebih dari 1 tahun di Hotel Sheraton Surabaya sehingga kuesioner yang bisa diolah berjumlah 72. Dari data yang diperoleh sebagian besar responden berjenis kelamin perempuan $(55,56 \%)$ dan berumur dari 26 sampai 35 tahun $(31,94 \%)$. Sebanyak 16 responden berasal dari departemen $F \& B$ Service $(22,22 \%)$ dan sudah bekerja selama 1-3 tahun $(41,67 \%)$.

Berdasarkan hasil uji validitas dan relibilitas, semua 20 indikator dinyatakan valid dan reliabel. Sedangkan hasil perolehan mean dapat dilihat pada tabel 1 . 
Tabel 1. Hasil Analisis Mean dan Standar Deviasi

\begin{tabular}{|c|c|c|c|c|}
\hline Kodee & Indikator & Std. Dev & Mean & Klasifikasi \\
\hline $\mathrm{X} 1$ & $\begin{array}{l}\text { Karyawan memiliki sikap tanggap terhadap konsumen dan rekan kerja } \\
\text { lainnya }\end{array}$ & 0,459 & 4,76 & Sangat Setuju \\
\hline $\mathrm{X} 2$ & Karyawan selalu ramah terhadap konsumen dan rekan kerja lainnya & 0,436 & 4,75 & Sangat Setuju \\
\hline $\mathrm{X} 3$ & Karyawan selalu suka menolong konsumen dan rekan kerja lainnya & 0,451 & 4,72 & Sangat Setuju \\
\hline $\mathrm{X} 4$ & $\begin{array}{l}\text { Karyawan selalu mencoba memposisikan diri sebagai konsumen atau } \\
\text { rekan kerja lainnya agar dapat mengerti sudut pandang dan masalah } \\
\text { yang dialami }\end{array}$ & 0,555 & 4,54 & Sangat Setuju \\
\hline X5 & $\begin{array}{l}\text { Karyawan bertanggung jawab di luar wewenang karyawan jika } \\
\text { iperlukan (misalnya dalam menangani keluhan konsumen dari } \\
\text { departemen lain) }\end{array}$ & 0,830 & 4,04 & Setuju \\
\hline X6 & $\begin{array}{l}\text { Karyawan ikut merasa sedih bila ada berita buruk mengenai Hotel } \\
\text { Sheraton }\end{array}$ & 0,575 & 4,58 & Sangat Setuju \\
\hline $\mathrm{X} 7$ & $\begin{array}{l}\text { Karyawan bersikap sesuai dengan identitas Hotel Sheraton, walaupun } \\
\text { sedang tidak diawasi. }\end{array}$ & 0,519 & 4,61 & Sangat Setuju \\
\hline X8 & $\begin{array}{l}\text { Karyawan berhati-hati dalam melakukan pekerjaan dan mengecek hasil } \\
\text { kualitas pekerjaannya, apakah sudah memberi dampak positif pada } \\
\text { identitas Hotel Sheraton }\end{array}$ & 0,554 & 4,56 & Sangat Setuju \\
\hline X9 & $\begin{array}{l}\text { Karyawan bersedia melakukan pekerjaan ekstra, jika dapat berdampak } \\
\text { positif pada citra Hotel Sheraton (menyelesaikan permintaan tamu } \\
\text { melebihi ekspetasi tamu) }\end{array}$ & 0,650 & 4,51 & Sangat Setuju \\
\hline $\mathrm{X} 10$ & $\begin{array}{l}\text { Karyawan membela Hotel Sheraton jika ada yang mengkritik Hotel } \\
\text { Sheraton }\end{array}$ & 0,659 & 4,37 & Sangat Setuju \\
\hline $\mathrm{X} 11$ & $\begin{array}{l}\text { Karyawan tidak mengeluh tentang upaya yang dilakukan untuk } \\
\text { menghasilkan citra Hotel Sheraton yang positif (seperti saat mengikuti } \\
\text { kegiatan sosial diluar jam kerja) }\end{array}$ & 0,751 & 4,33 & Sangat Setuju \\
\hline $\mathrm{X} 12$ & $\begin{array}{l}\text { Karyawan tidak mengeluh tentang kesulitan dan tugas yang } \\
\text { menjengkelkan dalam pekerjaan }\end{array}$ & 0,671 & 4,26 & Sangat Setuju \\
\hline $\mathrm{X} 13$ & $\begin{array}{l}\text { Karyawan akan tetap bekerja di Hotel Sheraton walau kompetitor } \\
\text { memberikan tawaran gaji yang lebih }\end{array}$ & 0,954 & 3,82 & Setuju \\
\hline $\mathrm{X} 14$ & $\begin{array}{l}\text { Karyawan akan selalu merekomendasikan Hotel Sheraton } \\
\text { ada teman, kenalan atau saudara }\end{array}$ & 0,691 & 4,46 & Sangat Setuju \\
\hline $\mathrm{X} 15$ & $\begin{array}{l}\text { Karyawan dapat menyampaikan nilai Hotel Sheraton saat } \\
\text { erinteraksi dengan konsumen }\end{array}$ & 0,552 & 4,57 & Sangat Setuju \\
\hline X16 & $\begin{array}{l}\text { Karyawan dengan aktif menanyakan feedback dari rekan kerja } \\
\text { ainnya }\end{array}$ & 0,716 & 4,22 & Sangat Setuju \\
\hline $\mathrm{X} 17$ & $\begin{array}{l}\text { Karyawan berusaha untuk mengembangkan keahlian dengan } \\
\text { membaca buku panduan atau jurnal profesional }\end{array}$ & 0,881 & 4,11 & Setuju \\
\hline X18 & $\begin{array}{l}\text { Karyawan mempunyai inisiatif untuk ikut dalam pelatihan secara } \\
\text { reguler }\end{array}$ & 0,747 & 4,32 & Sangat Setuju \\
\hline X19 & $\begin{array}{l}\text { Karyawan selalu melaporkan feedback dari konsumen atau masalah } \\
\text { internal langsung pada orang yang bersangkutan }\end{array}$ & 0,557 & 4,50 & Sangat Setuju \\
\hline \multirow[t]{2}{*}{$\mathrm{X} 20$} & $\begin{array}{l}\text { Karyawan mengambil inisiatif untuk mengembangkan ide engenai } \\
\text { produk, layanan atau perkembangan baru }\end{array}$ & 0,735 & 4,35 & Sangat Setuju \\
\hline & Rata-rata Mean & & 4,42 & Sangat Setuju \\
\hline
\end{tabular}

Tabel 1 menunjukkan bahwa sebagian besar responden sangat setuju terhadap indikator BCB di Hotel Sheraton Surabaya dengan nilai rata-rata mean sebesar 4,42. Nilai mean tertinggi adalah 4,76 yaitu indikator "Karyawan memiliki sikap tanggap terhadap konsumen dan rekan kerja lainnya" yang termasuk dalam klasifikasi sangat setuju. Sedangkan nilai mean terendah adalah 3,82 yaitu indikator "Karyawan akan tetap bekerja di Hotel Sheraton walau kompetitor memberikan tawaran gaji yang lebih" yang termasuk dalam klasifikasi setuju.

Hasil uji Kaiser-Meyer-Olkin (KMO) Measure of Sampling Adequacy sebesar 0.833 (> 0.500) dan signifikansi dari Berlett's Test sebesar 0.000 sehingga 
Tabel 2. Faktor Baru yang Terbentuk

\begin{tabular}{|c|c|c|c|}
\hline No & Nama Faktor & Variabel & Indikator \\
\hline \multirow[t]{8}{*}{1} & \multirow[t]{8}{*}{$\begin{array}{l}\text { Helping behavior } \\
45,760 \%\end{array}$} & $\mathrm{X} 1$ & $\begin{array}{l}\text { Karyawan memiliki sikap tanggap terhadap konsumen dan rekan kerja } \\
\text { lainnya. }\end{array}$ \\
\hline & & $\mathrm{X} 2$ & $\begin{array}{l}\text { Karyawan selalu ramah terhadap konsumen dan rekan kerja lainnya. } \\
\text { Karyawan selalu suka menolong konsumen dan rekan kerja lainnya. }\end{array}$ \\
\hline & & $\mathrm{X} 3$ & Karyawan berhati-hati dalam melakukan pekerjaan dan mengecek hasil \\
\hline & & & kualitas pekerjaannya, apakah sudah memberi dampak positif pada identitas \\
\hline & & $\mathrm{X} 8$ & Hotel Sheraton. \\
\hline & & & $\begin{array}{l}\text { Karyawan akan selalu merekomendasikan Hotel Sheraton pada teman, kenalan } \\
\text { atau saudara. }\end{array}$ \\
\hline & & $\mathrm{X} 14$ & $\begin{array}{l}\text { Karyawan selalu melaporkan feedback dari konsumen atau masalah internal } \\
\text { langsung pada orang yang bersangkutan. }\end{array}$ \\
\hline & & $\mathrm{X} 19$ & \\
\hline \multirow[t]{7}{*}{2} & \multirow{7}{*}{$\begin{array}{l}\text { Brand Enthusiasm } \\
8,407 \%\end{array}$} & X6 & Karyawan ikut merasa sedih bila ada berita buruk mengenai Hotel Sheraton. \\
\hline & & & Karyawan bersedia melakukan pekerjaan ekstra, jika dapat berdampak positif \\
\hline & & X9 & $\begin{array}{l}\text { pada citra Hotel Sheraton (menyelesaikan } \\
\text { permintaan tamu melebihi ekspetasi tamu). }\end{array}$ \\
\hline & & $\mathrm{X} 11$ & $\begin{array}{l}\text { Karyawan tidak mengeluh tentang upaya yang dilakukan untuk menghasilkan } \\
\text { citra Hotel Sheraton yang positif (seperti saat mengikuti kegiatan sosial diluar } \\
\text { jam kerja). }\end{array}$ \\
\hline & & & Karyawan dapat menyampaikan nilai Hotel Sheraton saat berinteraksi dengan \\
\hline & & $\mathrm{X} 15$ & konsumen. \\
\hline & & X20 & $\begin{array}{l}\text { Karyawan mengambil inisiatif untuk mengembangkan ide mengenai } \\
\text { produk,layanan atau perkembangan baru. }\end{array}$ \\
\hline \multirow[t]{5}{*}{3} & \multirow{5}{*}{$\begin{array}{l}\text { Self Development } \\
7,008 \%\end{array}$} & $\mathrm{X} 16$ & Karyawan dengan aktif menanyakan feedback dari rekan kerja lainnya. \\
\hline & & & Karyawan berusaha untuk mengembangkan keahlian dengan membaca buku \\
\hline & & $\mathrm{X} 17$ & panduan atau jurnal professional. \\
\hline & & & Karyawan mempunyai inisiatif untuk ikut dalam pelatihan secara regular. \\
\hline & & $\mathrm{X} 18$ & \\
\hline \multirow[t]{3}{*}{4} & \multirow[t]{3}{*}{$\begin{array}{l}\text { Brand Loyalty } \\
5,841 \%\end{array}$} & $\mathrm{X} 7$ & $\begin{array}{l}\text { Karyawan bersikap sesuai dengan identitas Hotel Sheraton, walaupun sedang } \\
\text { tidak diawasi. }\end{array}$ \\
\hline & & $\mathrm{X} 10$ & Karyawan membela Hotel Sheraton jika ada yang mengkritik Hotel Sheraton. \\
\hline & & $\mathrm{X} 13$ & $\begin{array}{l}\text { Karyawan akan tetap bekerja di Hotel Sheraton walau kompetitor memberikan } \\
\text { tawaran gaji yang lebih. }\end{array}$ \\
\hline
\end{tabular}

penelitian bisa dilanjutkan. Hasil MSA pada 20 indikator yang ada nilainya melebihi 0.500 sehingga semua indikator dapat digunakan untuk analisis lebih lanjut. Namun hasil communalities menyatakan bahwa variabel X5 tidak memenuhi syarat yaitu nilainya kurang dari 0.500 , sehingga variabel X5 tidak digunakan. Setelah melakukan penghitungan соттиnalities yang baru, maka diperoleh hasil bahwa ke-19 variabel nilainya diatas 0.500 yang berarti ke-19 variabel dapat menjelaskan faktor yang dianalisis. Penghitungan ulang juga dilakukan pada nilai KMO dan anti-image. Nilai KMO yang baru sebesar 0.839 dan signifikansi dari Berlett's Test sebesar 0.000 (> 0.500). Dengan demikian penelitian dapat dilanjutkan.

Berdasarkan hasil Total Varianced Explained dapat disimpulkan bahwa dari 19 variabel tersebut terbentuk 4 faktor baru. Kontribusi dari ke-4 faktor tersebut adalah $67,016 \%$. Berikut merupakan nama 4 faktor baru dan penjelasannya.

\section{Helping Behavior}

Terdapat 6 variabel pembentuk faktor ini. Sikap karyawan yang tanggap, ramah, dan suka menolong terhadap konsumen dan rekan kerja lainnya. Faktor ini memberikan kontribusi terbesar yaitu $45,760 \%$ pada BCB di Hotel Sheraton Surabaya, yang berarti faktor helping behavior yang paling dominan menjelaskan BCB di Hotel Sheraton Surabaya. Penemuan ini mirip dengan penelitian Burmann, Zeplin \& Riley (2008), Chiang, Chang \& Han (2012) dan Porricelli et al. (2014), yang juga mendapatkan nilai lebih tinggi pada faktor ini daripada faktor lainnya.

2. Brand Enthusiasm

Faktor ini sebesar 8,407\% menjelaskan faktor BCB di Hotel Sheraton Surabaya. Terdapat 5 variabel yang termasuk dalam brand enthusiasm. Penelitian Baumgarth \& Schmidt (2010) menyebutkan bahwa faktor brand enthusiam adalah salah satu dari 2 faktor BCB yang disebut dapat 
mewakili BCB. Brand enthusiasm berupa kesediaan karyawan untuk terlibat dalam merek meskipun dapat menimbulkan ketidaknyamanan dan sikap karyawan yang tidak suka mengeluh.

3. Self-Development

Faktor self development menjelaskan 7,008\% dari faktor BCB di Hotel Sheraton Surabaya. Terdapat 3 variabel yang termasuk dalam faktor ini, yaitu sikap aktif karyawan untuk meminta feedback bagi dirinya, sikap untuk meningkatkan keahlian, dan mempunyai inisiatif untuk partisipasi dalam pelatihan. Faktor self development berarti karyawan mempunyai kemauan untuk terus meningkatkan keterampilan individu, baik terkait pekerjaannya atau tidak.

4. Brand Loyalty

Terdapat 3 variabel dalam faktor ini, yaitu bersikap sesuai nilai organisasi walau tidak diawasi, membela organisasi, dan akan tetap dalam organisasi walau kompetitor memberi tawaran gaji lebih tinggi. Penamaan faktor ini berbeda dari penelitian terdahulu, karena ke-3 variabel ini mencerminkan kesetiaan pada organisasi sehingga peneliti memberi nama faktor baru brand loyalty. Faktor ini mampu menjelaskan BCB sebesar 5,841\% di Hotel Sheraton Surabaya. Meskipun faktor ini kontribusinya rendah, akan tetapi karyawan Hotel Sheraton Surabaya memiliki loyalitas pada tempat dimana karyawan bekerja.

\section{KESIMPULAN DAN SARAN}

\section{Kesimpulan}

Dalam penelitian ini karyawan di Hotel Sheraton Surabaya sudah memiliki sikap yang mencerminkan BCB, terutama dalam faktor helping behavior (sikap karyawan yang tanggap, suka menolong, dan dapat memposisikan diri sebagai pihak lain) yang mewakili $45,760 \%$. Faktor brand enthusiasm (karyawan bersedia untuk ikut terlibat dalam merek meskipun dapat menimbulkan ketidaknyamanan dan karyawan tidak mengeluh saat menghadapi kesulitan dalam pekerjaan) mewakili 8,407\%. Faktor self development (karyawan memiliki inisiatif unutk meningkatkan keahlian, baik dengan cara mengikuti pelatihan maupun membaca buku) mewakili 7,008\%; dan faktor brand loyalty (karyawan bersikap loyal terhadap Hotel Sheraton dengan bersikap sesuai identitas Sheraton dan membela Hotel Sheraton saat ada yang mengkritik) mewakili 5,841\% dari perilaku BCB di Hotel Sheraton Surabaya.

\section{Saran}

Berdasarkan hasil penelitian ini, dapat dilihat pada nilai mean terendah dari hasil penelitian adalah 3,82 pada indikator "Karyawan akan tetap bekerja di Hotel Sheraton walau kompetitor memberikan tawaran gaji yang lebih". Meskipun mendapat nilai mean yang rendah dibandingkan indicator yang lain, indikator tersebut tetap diklasifikasikan "setuju". Indikator ini termasuk dalam faktor baru brand loyalty. Oleh karena itu sebaiknya Hotel Sheraton Surabaya dapat meningkatkan reward yang berupa pemberian kartu ucapan terima kasih kepada karyawan ketika nama karyawan tersebut disebut oleh tamu hotel, baik dalam bentuk email maupun guest comment. Tujuannya adalah untuk membuat karyawan merasa lebih dihargai/diapresiasi. Dengan demikian, karyawan merasa adanya keterikatan dengan organisasi dan lingkungan dalam organisasi.

Secara keseluruhan nilai mean adalah 4,42 yang termasuk klasifikasi sangat setuju. Dengan demikian Hotel Sheraton Surabaya termasuk memiliki karyawan yang memiliki BCB tinggi. Oleh karena itu sebaiknya pihak hotel tetap mempertahankan dan bahkan meningkatkan BCB yang sudah dimiliki karyawan. Untuk meningkatkan BCB dapat dilakukan dengan cara meningkatkan rasa kepekaan antar sesama rekan kerja maupun terhadap konsumen dengan lebih sering mengadakan acara kebersamaan secara sederhana dan tetap aktif berpartisipasi dalam klub-klub yang sudah ada. Hal ini akan membuat hubungan antar karyawan semakin dekat dan lebih mengenal sesama karyawan serta nilai merek yang dimiliki oleh hotel.

Keterbatasan penelitian ini hanya dilakukan pada satu hotel sehingga ada kemungkinan hasil penelitiannya belum dapat menjadi acuan bagi banyak hotel. Oleh karena itu untuk penelitian selanjutnya, objek penelitian dapat diperluas pada seluruh hotel bintang lima di Surabaya atau Indonesia dengan melibatkan jumlah responden yang lebih besar untuk memperoleh hasil yang lebih valid.

\section{DAFTAR REFERENSI}

Badan Pusat Statistik Indonesia. (2016). Statistik hotel dan akomodasi lainnya di Indonesia. BPSStatistics Indonesia.

Badan Pusat Statistik Indonesia. (2018). Statistik hotel dan akomodasi lainnya di Indonesia. BPSStatistics Indonesia.

Baumgarth, C., \& Schmidt, M. (2010). How strong is the business-to-business brand in the workforce? 
anempirically-tested model of internal brand equity' in a business-to-business setting. Industrial Marketing Management, 39(8), 12501260. Retrieved from https://doi.org/10.1016/ j.indmarman.2010.02.022

Burmann, C., \& Zeplin, S. (2005). Building brand commitment: A behavioural approach to internal brand management. Journal of Brand Management, 12(4), 279-300. Retrieved from https://doi.org/10.1057/palgrave.bm.2540223

Burmann, C., Zeplin, S., \& Riley, N. (2008). Key determinants of internal brand management success: An exploratory empirical analysis. Journal of Brand Management, 16(4), 264-284. Retrieved from https://doi.org/10.1057/bm. 2008.6

Chiang, H.-H., Chang, A., \& Han, T.-S. (2012). A multilevel investigation of relationships among brand-centered HRM, brand psychological ownership, brand citizenship behaviors, and customer satisfaction. European Journal of Marketing, 46(5), 626 - 662. Retrieved from https://doi.org/10.1108/03090561211212458

Ghozali, I. (2005). Aplikasi analisis multivariat dengan program SPSS. Semarang: Badan Penerbit Universitas Diponegoro.

King, C., \& Grace, D. (2007). Internal branding: exploring the employee's perspective. Journal of
Brand Management, 15(5), 358-372. Retrieved from https://doi.org/10.1057/palgrave.bm.25 50 136

Piehler, R. (2018). Employees' brand understanding, brand commitment, and brand citizenship behaviour: A closer look at the relationships among construct dimensions. Journal of Brand Management, 25(3), 217-234. Retrieved from https://doi.org/10.1057/s41262-018-0099-z

Podsakoff, P. M., MacKenzie, S. B., Paine, J. B., \& Bachrach, D. G. (2000). Organizational citizenship behaviors: A critical review of the theoretical and empirical literature and suggestions for future research. Journal of Management, 26(3), 513-563. Retrieved from https://doi.org/10. 1177/014920630002600306

Porricelli, M. S., Yurova, Y., Abratt, R., \& Bendixen, M. (2014). Antecedents of brand citizenship behavior in retailing. Journal of Retailing and Consumer Services, 21, 745-752. Retrieved from https://doi.org/10.1016/j.jretconser.2014. 06.002

Prasad, K., \& Dev, C. S. (2000). Managing hotel brand equity: A customer-centric framework for assessing performance. Cornell Hospitality Quarterly, 41(3), 22-31. Retrieved from https:// doi.org/10.1177/001088040004100314 